\title{
A Integração Nacional analisada segundo a geopolítica brasileira entre 1910-1950
}

\section{The National Integration analyzed according to the Brazilian geopolitics between 1910-1950}

Rev. Bras. Est. Def. v. 7, nº 1, jan./jun. 2020, p. 97-124

DOI: $10.26792 /$ RBED.v7n1.2020.75157

ISSN 2358-3932

\section{GREGOR G. A. A. DE ROOY HÉLIO CAETANO FARIAS}

\section{INTRODUÇÃO}

Este estudo consulta os revisores contemporâneos da geopolítica brasileira para identificar os mais destacados autores do assunto entre as décadas de 1910 e 1950, com o propósito de verificar se há um argumento em comum entre as suas principais obras que seja caracterizador do pensamento geopolítico brasileiro neste período. Para este fim, recorremos às obras de Jorge Manuel da Costa Freitas autor de A Escola Geopolítica Brasileira (Freitas 2004), de Wanderley Messias da Costa, autor de Geografia Política e Geopolítica: Discursos Sobre o Território e o Poder (Costa 1992), e de Shiguenoli Miyamoto, autor de Geopolítica e Poder no Brasil (Miyamoto 1995). A partir destas, selecionamos e analisamos as publicações dos autores brasileiros de geopolítica de maior destaque entre as décadas de 1910 e 1950. Entre os achados desta pesquisa, destaca-se que o principal argumento em comum destes geopolíticos era de que para melhor defender-se o Brasil precisaria melhor integrar-se.

$\mathrm{O}$ recorte temporal deve-se à continuidade verificada no pensamento geopolítico brasileiro entre seu início, na década de 1910, e a década de

\footnotetext{
Gregor G. A. A. de Rooy - Cientista Social pela Universidade Federal de Pernambuco (UFPE), especialista em Diplomacia e Negócios Internacionais pela Faculdade Damas da Instrução Cristã, Mestre em Ciências Militares pelo Instituto Meira Mattos (IMM) da Escola de Comando e Estado Maior do Exército (ECEME). Doutorando em Ciências Militares por esta mesma Escola. É membro do Grupo de Pesquisa “Geopolítica, Defesa e Desenvolvimento”, registrado no CNPq.

Hélio Caetano Farias - Graduado e Mestre em Geografia pela Universidade Estadual de Campinas (Unicamp). Doutor em Economia Política Internacional pela Universidade Federal do Rio de Janeiro (UFRJ). Professor Adjunto do Programa de Pós-Graduação em Ciências Militares (PPGCM) do Instituto Meira Mattos (IMM) da Escola de Comando e Estado Maior do Exército (ECEME). É Coordenador do Grupo de Pesquisa "Geopolítica, Defesa e Desenvolvimento", registrado no CNPq.
} 
1950. Optou-se por limitar o estudo até a década de 1950. A justificativa para tal deve-se a inferência de que as ideias e conceitos-chave que caracterizam o pensamento geopolítico brasileiro foram edificados no período indicado. Sendo, inclusive, referência à compreensão da geopolítica a partir dos anos 1960 (Costa 1992; Théry 2012; Farias 2017; Rooy 2019).

\section{O PRINCÍPIO DA GEOPOLÍTICA NO BRASIL}

De acordo com Miyamoto (1995), o documento "Geopolítica”, publicado pela ESG em 1977, considera:

como pioneiros do pensamento geopolítico brasileiro, nos terrenos das incursões práticas, Alexandre de Gusmão — responsável pelo Tratado de Madrid, o Visconde do Rio Branco e o Barão do Rio Branco, todos antecipando-se a Backheuser (cf. ESG apud Miyamoto 1995). ${ }^{1}$

Embora Miyamoto (1995), assim como Costa (1992) e Freitas (2004), entendam que Backheuser (1926), foi o primeiro nacional a fazer referência à geopolítica em seu "A estrutura política do Brasil. Notas prévias", de 1926, Miyamoto (1995) faz uma observação sobre a contribuição de Elysio de Carvalho quando este diz em "O fator Geográfico na Política Brasileira" (Carvalho 1921), o seguinte: "A sorte das nações está inevitavelmente ligada à fatalidade geográfica e é por isso que não concebemos uma política brasileira alheia do seu mapa" (Carvalho apud Miyamoto 1995, 47). Ou seja, já em 1921, ao analisar as relações entre política e geografia no Brasil, Elysio relacionava elementos essenciais à geopolítica tais como território e poder. ${ }^{2}$

O estudo de Freitas (2004) também menciona a relevância dos trabalhos de geografia militar do, à época, coronel do exército Francisco de Paula Cidade e dos trabalhos de geografia política do professor Delgado de Carvalho. Segundo Miyamoto (1995), cujo ponto é corroborado por Freitas (2004), a contribuição de Delgado de Carvalho, principalmente na obra "Introdução à Geografia Política” (Carvalho 1929), destaca-se por ter englobado em sua análise "as noções de espaço, forma, posição e poder" (Miyamoto 1995, 57). Além disso, Miyamoto faz uma ressalva importante sobre a primeira contribuição de Delgado de Carvalho para os demais geopolíticos. O autor diz:

Não se deve, contudo, minimizar a importância de Delgado de Carvalho. Foi ele, após seu regresso da França, que alterou radicalmente a forma de abordar a geografia - até então preocupada apenas com o simples arrolamento de dados - , analisando-a sob um novo ângulo. Sua influência faz-se sentir desde 1913, quando publicou Geografia do Brasil, até o final da década de 1970 (Miyamoto 1995, 57). 
Com relação às contribuições de Cidade, tanto Miyamoto (1995) quanto Freitas (2004) consideram que o autor foi um dos percussores da geopolítica, embora tenha recebido pouco destaque dos revisores da geopolítica brasileira. O estudo de Cidade, Notas de Geografia Militar Sul-Americana (1940), tem um traço pertinente, e que é um dos pontos centrais do argumento deste texto, a saber: a relevância das "vias de comunicação" ${ }^{3}$ para a formação do território nacional e para a defesa nacional. Esse mesmo aspecto é percebido em Delgado de Carvalho, em 1913, com a publicação do livro "Geografia do Brasil" (Carvalho 1913). Os demais autores de geopolítica, tais quais Everardo Backheuser, Lysias Rodrigues (1947), Mario Travassos (1947) e Golbery do Couto e Silva (1952; 1959) são reconhecidos pelos revisores como autores fundamentais. ${ }^{4 / 5}$

Identifica-se, nesta revisão, que as obras de geopolítica consultadas, de maneira geral, dividem-se em dois grandes temas: i) $\mathrm{O}$ temor da desintegração nacional; e ii) Reflexões sobre ameaças externas. Nas obras de Everardo Backheuser (1933; 1948) e de Lysias Rodrigues (1947), há mais consternação com os perigos de ímpetos regionalistas, que poderiam ter como consequência o separatismo. Nos trabalhos de Cidade (1940), Mario Travassos (1947) e Golbery do Couto e Silva (1952; 1959), identificou-se maior preocupação com ameaças externas. Portanto, a leitura desses autores não será na ordem cronológica de suas publicações, mas sim em relação aos tópicos 1 e 2. Em um primeiro momento, apresenta-se os estudos de Backheuser e Rodrigues, para, em seguida, verificar as contribuições de Cidade, Travassos e Couto e Silva. A explanação começa com a obra de Delgado de Carvalho, por ser considerado um dos primeiros influenciadores dos demais geopolíticos.

\section{A GEOPOLÍTICA BRASILEIRA ENTRE 1910-1950}

A obra Geografia do Brasil (1913) está dividida em três sessões "A Geographia Physica”, a "Geographia Economica” e "A Geographia Social”. Na última sessão, Delgado de Carvalho (1913) analisa o que chama de Formação Política do Brasil e sua Formação Social. Na seção da "Formação Política”, Carvalho, além de analisar os mecanismos ou instituições que administravam o interesse do estado na Colônia e no Império, estuda principalmente como o Estado português e, consecutivamente, o Estado brasileiro cresceram dentro da América do Sul. Delgado de Carvalho (1913) discorre sobre os diversos tratados internacionais ${ }^{6}$ firmados entre Portugal e Espanha e, depois, entre o Brasil e a Argentina, Bolívia, Uruguai, Espanha, os Países Baixos, a França, o Reino Unido e, ainda, entre os demais países que se formaram a partir da independência da Espanha. 
O autor também analisa como se deu a marcha de portugueses e brasileiros para o oeste da América do Sul. Em sua perspectiva, a colonização do sertão nordestino no século XVII se deu por motivos econômicos, pela necessidade de repelir os indígenas e como resposta à invasão holandesa no litoral da Bahia e de Pernambuco, que forçou a fuga da população que ali vivia para o interior (Carvalho 1913). No fim daquele mesmo século, o autor destaca as missões jesuítas, franciscanas e carmelitas à região amazônica; já no século XVIII, são observados os movimentos de portugueses para o sul, que resultaram na expulsão dos espanhóis do Uruguai para o oeste (Mato-Grosso e Goiás) e o contínuo esforço de habitação do Norte e do Nordeste (Pará e Maranhão). No século XIX, Carvalho lembra a criação do Estado do Amazonas e do território federal do Acre como sinais da consolidação do avanço do Estado brasileiro ao interior da América do Sul (Carvalho 1913).

Em paralelo a esses avanços, o autor também discorre sobre as "vias de comunicação” exploradas pelos portugueses e brasileiros ao longo desses séculos. Dentre elas, destacam-se o Rio São Francisco como hidrovia; os cursos de água de São Paulo ao Paraná, que correm do litoral ao interior; e os demais rios conectando com as Bacias do Prata e a Amazônica.

A relação entre a defesa e a formação do território nacional é percebida na própria maneira pela qual Carvalho organiza seu estudo, vindo primeiro a tratar do descobrimento das terras sul-americanas, para depois se referir à necessidade de sua defesa e, consequentemente, expansão. Esta ocorreu a par de confrontos com índios e espanhóis, e do desenvolvimento das "vias de comunicação" (Carvalho 1913).

Ainda no que diz respeito à formação do território nacional, Lysias Rodrigues (1947) em seu livro Geopolítica do Brasil, entre outros tópicos, analisa essa formação ao longo da história e aponta os desafios de integração nos diferentes períodos: o Colonial (1530-1822), o Imperial (18221889), o Republicano (1889-1930) e o período Revolucionário (1930-1945). Rodrigues (1947) começa sua investigação sobre a integração nacional a partir do Tratado de Tordesilhas (1494).

Dentre os desafios para a manutenção de um governo único no período colonial, Rodrigues (1947) menciona a dificuldade das "comunicações", diga-se, a insuficiência de meios de transporte e infraestrutura para manter o território coeso, ao passo que centros urbanos iam se formando e polarizando diferentes regiões, conforme percebemos na seguinte passagem:

À proporção que esses centros iam se tornando, por seus próprios recursos, autônomos, ia se subdividindo e enfraquecendo a força do governo, tanto mais quanto maiores as distâncias e as dificuldades das comunicações. Pela livre ação dos fatores geográficos, passou-se 
da fragmentação do poder à sua subdivisão, depois à pulverização, chegando-se mesmo, no hinterland, à completa anulação do poder (Rodrigues 1947, 52).

Apesar desses desafios, a fragmentação territorial do Brasil Colônia não ocorreu. As dificuldades de integração e controle do território continuaram durante o período, denominado por Rodrigues, de Brasil Império, que se inicia após a declaração de independência (1822). Sobre essa dificuldade, Rodrigues escreve:

O Brasil imperial recebe do Brasil colônia, por herança, um território espalhado em quase vinte partes autônomas, como pequeníssimas, senão nulas, relações de interdependência. Não estava ainda concretizado o sentimento de uma pátria única, nem se sentiam membros da mesma família as várias capitanias, transformadas então em províncias imperiais (...). Os estadistas do império enfrentavam, portanto, o problema dominante e supremo da unidade nacional (Rodrigues 1947, 53).

Ainda, segundo o autor, "o trunfo unificador do Estado Brasileiro foi a figura centralizadora do Imperador” (Rodrigues 1947, 54). Uma solução artificial, segundo Rodrigues. Para que a solução fosse decisiva "era preciso que tivesse sido resolvido o problema da circulação do país” (Rodrigues 1947 , 54), algo que começou a ser remediado com mais vigor no fim do período "Brasil Império", como diz o autor:

Os últimos anos do império no Brasil distinguem-se principalmente pela energia empregada em manter o contacto mais íntimo do centro dirigente com as diversas províncias. Surgem as ferrovias, o telégrafo, o cabo submarino, as primeiras rodovias, as companhias de navegação marítimas e fluviais, procurando levas de vencida, a todo o transe, a fôrça isolante do deserto, e conquistar essa circulação sem a qual é impossível obter a unidade política (Rodrigues 1947, 54).

Com o fim do Império, o conjunto dessas ações não tiveram continuidade. No período republicano, Rodrigues (1947) identifica a ameaça do municipalismo associada aos regionalismos de caráter separatista. A solução pensada, dessa vez, novamente considerou a criação de rodovias e incluiu a ampliação das redes telegráfica, ferroviária, telefônica e radiotelegráfica e, por fim, aérea (Rodrigues 1947). Contudo, as diversas instabilidades políticas desse período impediram, efetivamente, a implementação de um plano de integração nacional.

O período Revolucionário a que Rodrigues (1947) se refere é aquele que inicia em 1930. Com os quinze anos de governo de Getúlio Vargas (1930- 
1945), as soluções para a integração nacional incluem a implementação de uma rede de aerovias, de postos radiotelegráficos; estímulos da navegação marítima e fluvial, planos nacionais rodoviário e ferroviário; e o combate a tendências separatistas, chamadas pelo autor de "regionalismos doentios" (Rodrigues 1947, 57). Essa implementação ocorreu de maneira lenta, dada a dimensão continental do país e a escassez de recursos. Somente na segunda metade do século XX os grandes projetos e planos de integração nacional tiveram êxito.

Outra solução integradora levantada por Rodrigues seria a mudança da Capital Federal, do Rio de Janeiro para o interior do país. Essa mudança, de amplo significado geopolítico, representaria para a defesa a possibilidade de maior proteção quanto aos ataques aéreos e marítimos, ao mesmo tempo que seria um trunfo estratégico e econômico para forçar a abertura de vias de comunicação em direção ao centro do país, o que, consequentemente, provocaria "uma maior valorização do elemento humano ali localizado, um melhor índice econômico de todo o interior, com um incentivo crescente aos mais variados setores das atividades nacionais" (Rodrigues 1947, 108-9).

Para Rodrigues, a questão da integração nacional era central. A escassez das vias de comunicação poderia criar um contexto propício aos ímpetos separatistas. Logo, sua primeira preocupação era em relação à segurança doméstica, já que um movimento de fragmentação do território poderia levar a uma situação de confronto interno e comprometimento da segurança nacional (Rodrigues 1947).

Por outro lado, o desenvolvimento de vias de comunicação também deveria ser aplicado para mitigar fragilidades do Brasil em relação aos seus vizinhos da América do Sul, nas regiões chamadas pelo autor de "Puncti dolentes”. Os Puncti Dolentes seriam o Punctum de Iguaçu na região de Iguaçu, fronteira do Brasil com a Argentina e o Paraguai; o da Bolívia, na região do triângulo formado pelas cidades bolivianas de Cochabamba-Sucre e Santa Cruz de La Sierra, como indicado na Figura 3; e o Punctum de Letícia na fronteira de trijunção do Brasil, Peru e Colômbia.

O primeiro Punctum Dolens poderia representar uma zona de interesse de paraguaios e, principalmente, argentinos, por ser uma região desabitada do lado brasileiro e por ser a região das quedas d'água “dos rios Paraná e Iguaçu, capazes de produzirem um elevado potencial elétrico” (Rodrigues $1947,64)^{7}$

Já o segundo Punctum Dolens é assim chamado por Rodrigues por ser o "ponto de aplicação das forças resultantes dos antagonismos oceânicos que solicitam o conjunto continental sul-americano" (Rodrigues 1947, 65). Esse punctum em específico analisaremos com maior perícia adiante quando estudarmos a obra de Mário Travassos Projeção Continental do Brasil 
(Travassos, 1947), já que Rodrigues se refere a ela para explicar sua importância estratégica.

O terceiro Punctum Dolens é destacado pelo autor por ser uma região instável, com a presença de contingentes armados, sendo ainda "um grande nó dos diversos sistemas de transportes que buscam a porta de entrada do rio Amazonas" (Rodrigues 1947, 66), a instabilidade da região tinha o potencial de "estender-se pela calha amazônica e países vizinhos" (Rodrigues 1947, 66).

Para Rodrigues, a solução para dirimir a vulnerabilidade nos Puncti seria, antes de militar, econômica e logística, ou mesmo com criação de novos territórios (federais ou estados) dentro do Brasil. Sobre o Punctum da Bolívia, Rodrigues (1947) discorre sobre a importância da ferrovia BrasilBolívia, como vetor da influência brasileira no triângulo de CochabambaSucre e Santa Cruz de La Sierra. A respeito do Punctum de Letícia, a logística existente na região era vista com ressalva, pois o desenvolvimento de novas linhas de navegação fluviais e aéreas fizeram da região um centro "capaz de fazer fletir até ali rotas aéreas comerciais, que busquem ou venham da América do Norte, como o fềz o fator do Canal do Panamá" (Rodrigues 1947, 66). Para Rodrigues (1947) a solução seria a criação de um território federal do lado brasileiro da fronteira, associado a incentivos para o desenvolvimento econômico e povoamento da região.

Por fim, a resposta ao Punctum de Iguaçu também incluiria a criação de um território federal, o território de Iguaçu, e o incentivo ao desenvolvimento econômico da região, com "saídas" do Paraguai para o resto do mundo, que estavam em curso por meio da criação de linhas aéreas, ferrovias e melhora nos serviços de navegação do rio Paraguai (Rodrigues 1947).

Em conclusão, percebe-se que a integração nacional por meio das "vias de comunicação" era elemento sine qua non para o melhor desenvolvimento econômico do país e para viabilizar maior presença do Estado brasileiro em seu território, por vezes desabitado, o que teria como desdobramento atividades econômicas e o povoamento, principalmente na região do Planalto Central, com a Capital Federal, e na região amazônica. O desenvolvimento das vias de comunicação teria o duplo propósito: reduzir o risco de tendências separatistas, associado ao povoamento de regiões desabitadas; e a ampliação da presença militar e econômica, capacitando a defesa do Brasil diante dos Puncti Dolentes identificados.

Anterior a Rodrigues (1947), a preocupação com a dimensão do território nacional e a divisão dos estados brasileiros foi tema estudado por Everardo Backheuser em Problemas do Brasil (estrutura geopolítica) (Backheuser 1933). Nesse livro, o autor apresentou a histórica preocupação do Estado brasileiro com o controle de estados ou províncias de 
grandes dimensões, assim como dos diversos regionalismos no Brasil, que poderiam desencadear ímpetos separatistas (Backheuser 1933). Caberia ao governo central, portanto, lidar com esses ímpetos por meio da criação de unidades federais equipotentes com dimensões, peso político e econômico similares e submetidas a um poder central forte (Backheuser 1933). ${ }^{8}$

Sobre a importância da integração, Backheuser (1933) tratou da necessidade da criação de nova Capital Federal, que deveria ocupar posição central no interior, Planalto Central, conforme percebido na seguinte passagem:

A organização política faz com que a capital seja o centro de irradiação das vias de comunicação, ao mesmo tempo que o celeiro principal de abastecimentos, que seja enfim o ponto principal do país cuja posse é disputada com energia por agressores e nacionais (Backheuser 1933, 130).

A integração nacional por meio das vias de comunicação é mais bem analisada em Curso de Geopolítica Geral e do Brasil (Backheuser 1948). O tópico é explorado como importante elemento dissuasório que deve ser implementado em associação com o povoamento do território, já que o povoamento poderá prover melhor reação do país a pressões externas. Como diz Backheuser: "É de grande valor, portanto, o 'enchimento' humano do território. Acha [Alexander] Supan que, graças a isto, pode haver melhor reação - pacífica e guerreira — às pressões externas” (Backheuser 1948, 74).

Assim, a infraestrutura de transporte, chamada por Backheuser de "elemento circulatório" estaria a serviço do povoamento do território e emergiria como "elemento centrípeto na vida política do Estado" (Backheuser $1948,74)$. Ou seja, garantiria uma resposta às pressões externas e integraria o território mitigando os riscos de separação. Por fim, a importância da integração é destacada como um meio para o país vivificar/habitar a faixa de fronteira ou regiões próximas. Para isso, seria necessário "procurar a valorização desse hinterland já pelo povoamento, já por fáceis comunicações com o resto do país" (Backheuser 1948, 249).

Os estudos desses três autores, Delgado de Carvalho (1913), Backheuser (1933; 1948) e Rodrigues (1947), ilustram a atenção que dedicaram à formação do território nacional. O que se destaca da obra de Delgado de Carvalho é a sua análise da formação do território e, com ela, do surgimento e desenvolvimento das "vias de comunicações". Já Rodrigues (1947) e Backheuser (1933; 1948), além de terem analisado essa formação, tiveram em comum a preocupação com a integridade territorial, ameaçada pelos regionalismos também chamados de forças centrífugas. As soluções, tanto para Rodrigues como para Backheuser, incluiriam uma nova divisão do ter- 
ritório nacional, um incentivo ao povoamento de regiões de baixa densidade demográfica, notadas principalmente na região Norte e Centro-Oeste, e ainda a mudança da capital do Rio de Janeiro para o centro do país. A outra solução passaria pelo melhoramento da infraestrutura dos meios de transportes, em especial nas regiões mais ermas do país.

Tanto para Backheuser (1933; 1948) quanto para Rodrigues (1947), um Brasil verdadeiramente integrado seria capaz de diminuir os ímpetos regionalistas, as pressões externas, como diz Backheuser, como também melhor lidaria com os desafios dos Puncti Dolentes apontados por Rodrigues. Assim, esta revisão identificou a importância que Backheuser e Rodrigues deram à integração nacional, implementada pela construção das vias de comunicação, para a manutenção do território. Essa integração seria necessária para a segurança tanto interna como externa do país.

Já o estudo de Cidade, "Notas de Geografia Militar Sul-Americana" (Cidade 1940), propôs compreender todos os países da América do Sul e as colônias europeias no continente ${ }^{9}$ sob os seguintes aspectos: o governo e sua posição astronômica, sua superfície, suas fronteiras, história, fisiografia, hidrografia, regiões naturais, vegetação, população e centros habitados, viação, indústria e comércio, economia/finanças e forças armadas.

Enquanto os autores até aqui citados estudaram a questão da integração nacional em relação à formação e ao controle do território, centralizando as preocupações nas temáticas da integridade territorial e segurança; Cidade (1940) analisou a importância das vias de comunicação do território para a capacidade militar de resposta às ameaças externas, sobretudo dos Estados vizinhos.

A viação seria fundamental para a movimentação de tropas, como coloca Cidade:

As estradas de ferro, as estradas de rodagem, as vias navegáveis convenientemente equipadas, etc., ainda representam uma das maiores expressões da ação geográfica do homem. É talvez por isso que desempenham um papel tão importante em todas as fases da guerra (Cidade 1940, 58).

Seu estudo expõe maior preocupação com as habilidades do Estado brasileiro em garantir capacidade de movimentação à sua tropa na região da Bacia do Prata, em razão tanto das reminiscências da guerra contra o Paraguai quanto das preocupações com o poder da Argentina. Sobre as vulnerabilidades da Bacia Amazônica, o autor não dedica muita atenção, já que eram precárias, em todos os países da Bacia, as condições de transporte na região (Cidade 1940). Além disso, o Rio Amazonas funcionaria como um trunfo para o Brasil, pois o país poderia: "concentrar o seu exército 
onde mais lhe convenha e desferir golpes poderosos contra os seus adversários separados entre si” (Cidade 1940, 320).

A busca por uma combinação positiva entre meios de transporte e dissuasão, propiciada pela movimentação das tropas, fica mais clara quando Cidade (1940) se referiu à importância das fronteiras, como coloca o autor:

As vias férreas, mais ou menos retilíneas normais à fronteira, prestam-se não só à defensiva, mas principalmente à ofensiva. Nem sempre correspondem perfeitamente a todos os aspectos comerciais; porém, levam rapidamente aos pontos visados pelo comando superior; quando são paralelas à fronteira, prestam-se a deslocamentos laterais, isto é, a movimentos de rocada, destinados a concentrar onde fôr conveniente os elementos de ataque ou de defesa, transportados pelas vias normais à linha fronteiriça. (Cidade 1940, 60)

Percebe-se que a importância dos meios de transporte transparece em seu estudo como condicionadora de melhores e mais eficazes empregos da força militar do Brasil. Na passagem a seguir fica clara a preocupação com a Argentina, assim como a importância da infraestrutura de transporte como elemento fundamental das condições de ataque ou defesa:

O panorama geo-militar altera-se ao afastar-se da bacia amazônica, mas a situação dos vizinhos não melhora consideravelmente até atingir à fronteira argentina: tanto os vizinhos como o Brasil não dispõem de meios de transportes adequados, pelo menos até este momento.

Já se vê que o envolvimento do Brasil pelos seus vizinhos tem apenas uma expressão geométrica, sem nenhum significado militar, uma vez que, no estado atual da viação sulamericana, não se pode falar numa ação conjunta de todos os estados de origem espanhola contra o seu vizinho de origem lusa, cuja política tem sido sempre orientada pelos mais elevados sentimentos de justiça e de aproximação continental" (Cidade 1940, 321).

Se Cidade (1940) analisou de forma mais diplomática o potencial de tensões entre o Brasil e os países vizinhos, o à época, capitão de Exército Mário Travassos, autor de Projeção Continental do Brasil, publicado em $1931,{ }^{10}$ parece discordar desse ponto.

\section{INTEGRAÇÃO E PROJEÇÃO CONTINENTAL:TRAVASSOS E GOLBERY}

Em seu livro, Travassos (1947) avalia qual deveria ser a estratégia logística brasileira à luz da concorrência com dois países americanos: a Argentina e os Estados Unidos. Segundo Travassos (1947), a principal 
preocupação do Brasil nesse cenário deveria ser evitar a influência dos dois principais concorrentes do país à época ao desenvolver a infraestrutura de meios de transporte na América do Sul por meio de uma política de investimentos (Travassos 1947).

O primeiro concorrente do Brasil seria a Argentina, que desafiava a hegemonia do país na Bacia do Prata, projetando seus interesses sobre o Chile, a Bolívia e o Paraguai. O outro concorrente seriam os EUA, dada a sua influência sobre a América Central, notadamente sobre o Canal do Panamá e o Norte da América do Sul, motivado pela exploração do petróleo e da borracha (Travassos 1947).

Para Travassos, seria apenas desenvolvendo a infraestrutura de transporte - seja na terra, nas vias navegáveis ou no ar - que o Brasil poderia proteger seus interesses na América do Sul e impedir a expansão de influência da Argentina e dos EUA (Travassos 1947). Assim, o desenvolvimento das vias de comunicação do Brasil teria que se concentrar nas regiões Centro-Oeste, para fazer frente à Argentina, e Norte, para fazer frente aos EUA e à projeção Argentina nos Andes.

O olhar geopolítico de Travassos para a América do Sul partiu da identificação de dois fundamentais antagonismos geográficos, o primeiro, oceânico (Pacífico-Atlântico), o segundo, fluvial (Bacia do Prata-Bacia Amazônica). Este segundo antagonismo "interessando diretamente a vertente atlântica” (Travassos 1947, 43), ou seja, ao Brasil. Abaixo segue a figura formulada por Travassos (1947), uma representação cartográfica importante por mostrar minimamente aspectos da realidade geográfica e suas condicionantes. 


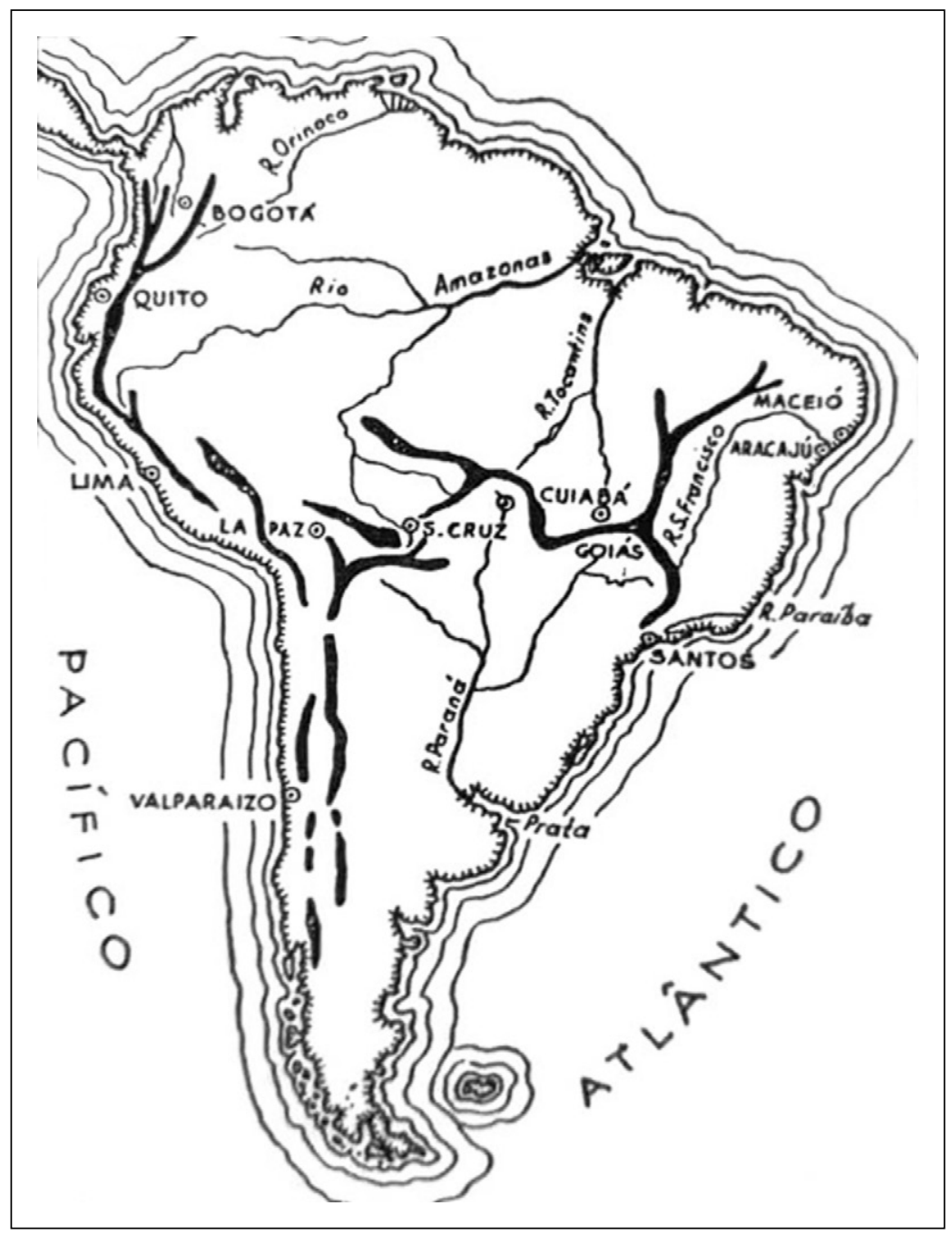

Figura 1 - Linhas que condicionam os antagonismos continentais. Fonte: Travassos $(1947,45)$. 
O primeiro antagonismo é o de uma América do Sul dividida pela Cordilheira dos Andes, que faz com que os países a seu leste estejam virados para o Pacífico, "o 'mar solitário', o oceano de feixes de circulação regionais, das extensões sem fim, das grandes profundidades, das polinésias” (Travassos 1947,43 ) e que os países a seu oeste estejam virados para o Atlântico, "cujas águas são as mais frequentadas do globo, em cujas costas o ecúmeno marítimo se encontra magnificamente definido e onde o 'planalto continental' é dos mais piscosos" (Travassos 1947, 44).

Devido às dimensões do Oceano Pacífico, ao parco comércio entre a América do Sul e a Ásia e Oceania na época; à ainda recente exploração das vias que se estabeleciam a partir do Canal do Panamá; e às já conhecidas vias de comunicação do Chile, do Peru e da Bolívia com a Argentina e o Porto de Buenos Aires, o primeiro antagonismo não recebe muito a atenção de Travassos, pois o Oceano Atlântico tinha mais importância do que o Pacífico. Portanto, o antagonismo sobre o qual o autor trabalha é o segundo, onde o Brasil concorreria com a Argentina e os EUA, por meio de sua infraestrutura de transporte, tanto na Bacia do Prata como na Amazônica.

É notória sua preocupação com as ligações por terra, principalmente de ferrovias, entre a Argentina e o Paraguai, o Chile e a Bolívia. Com a capacidade de circular pessoas e mercadorias entre esses três países e escoar produtos para o Atlântico através de Buenos Aires, a desenvoltura logística da Argentina era vista como ameaça à hegemonia brasileira no continente. Travassos descreveu a "Projeção Ferroviária" (Travassos 1947) da Argentina assim:

Como se vê, Buenos Aires está ligada, diretamente, por estrada de ferro, com as capitais de três países limítrofes. Com Assunção, dobrando a via fluvial e, de passagem, assegurando o contato (Concórdia-Salto) entre as redes argentina e uruguaia. Com Santiago (e Valparaíso) por meio da via férrea de montanha que vincula a riqueza andina com o Atlântico. Com La Paz, pela soldagem em Tupiza, da via argentina, com as linhas bolivianas, após seus trilhos percorrerem até La Quiaca a bagatela de $1.795 \mathrm{~km}$. (53-5).

Na Figura 2, a seguir, notamos as ligações de Buenos Aires: 


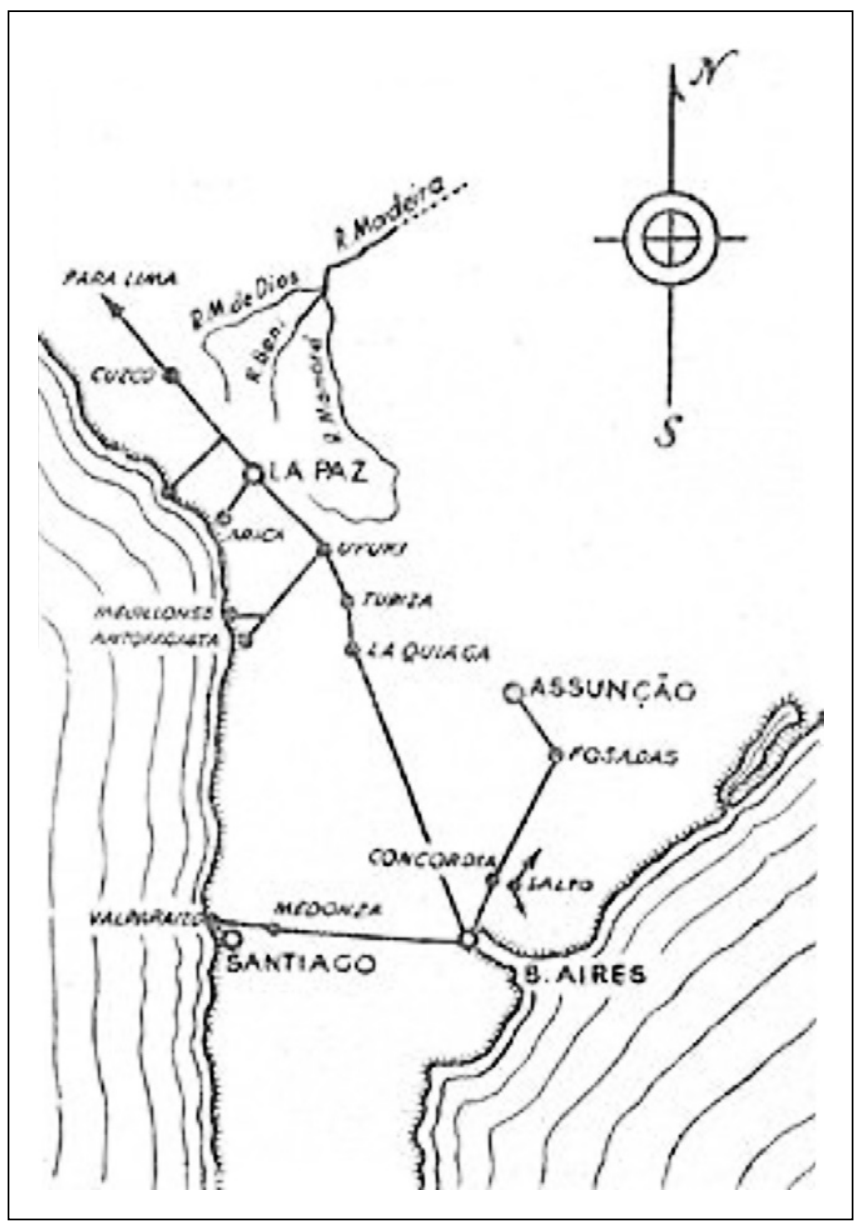

Figura 2 - Esquema do Esforço Ferroviário Platino.

Fonte: Travassos $(1947,54)$.

Além de destacar a importância da malha ferroviária entre a Argentina e o Paraguai e a Argentina e o Chile, a atenção de Travassos se voltou para a projeção Argentina na Bolívia. Segundo Travassos, "da ligação Buenos Aires-La Paz advêm reflexos capazes de repercussão até mesmo sobre a economia continental" (Travassos 1947, 56). Isso se daria principalmente pela ligação por via férrea entre La Paz e Cuzco (Peru) e La Paz e Arica (Chile), o que seria vantajoso para Buenos Aires, que poderia escoar para o Atlântico os diversos produtos tanto do Peru, como do Chile e da Bolívia. 
Essa "projeção férrea" da Argentina também usufruiria de uma segunda vantagem. Ela estaria ligada ao triângulo formado pelas cidades bolivianas de Sucre, Cochabamba e Santa Cruz de la Sierra (Figura 3), chamado por Travassos de verdadeiro signo da riqueza boliviana devido a seus recursos naturais. Na Figura 3, identifica-se a linha escura com traçados que representa os caminhos através dos quais a Argentina mantinha a sua "projeção férrea”, e o "triângulo" ao qual Travassos se refere:

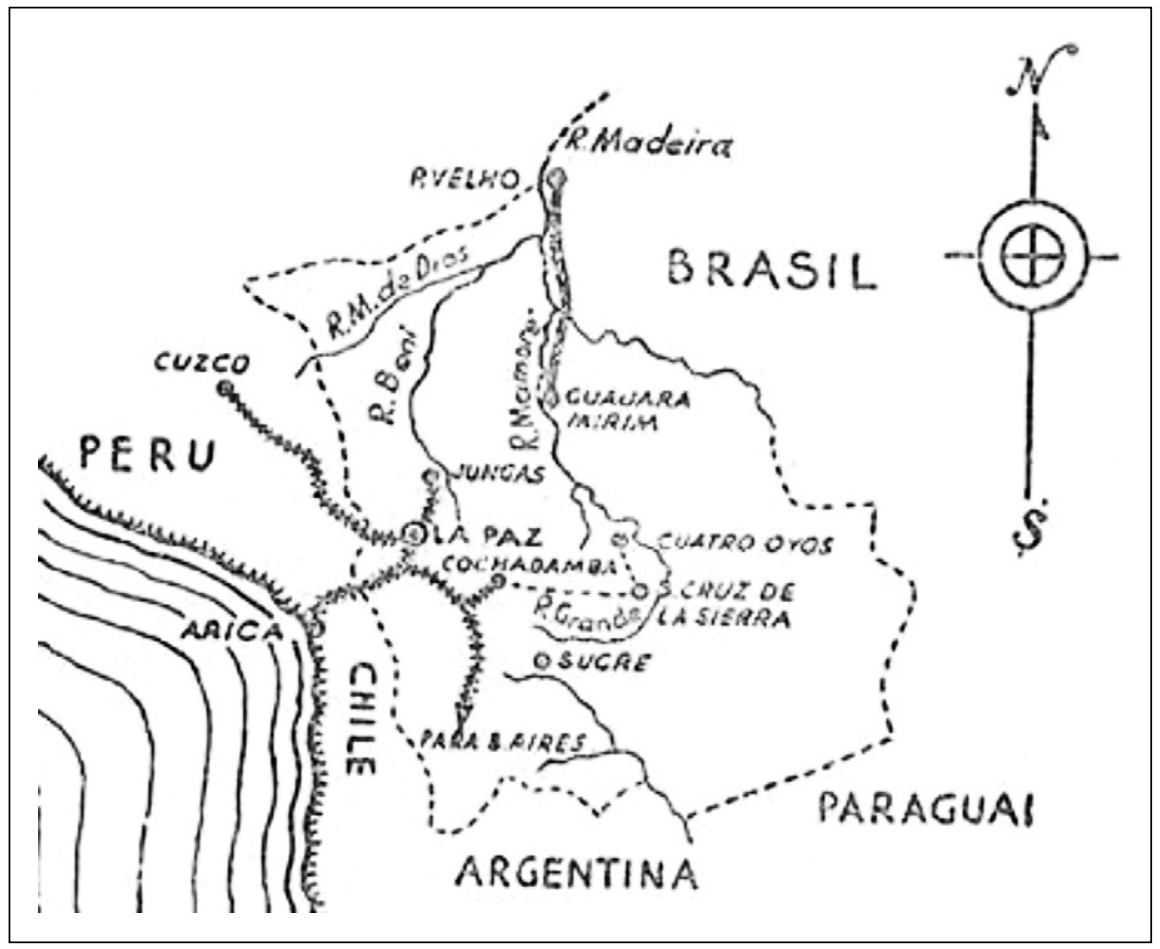

Figura 3 - Esquemas da Possibilidade de reação das comunicações da Bacia Amazônica sobre a política ferroviária platina.

Fonte: Travassos $(1947,63)$.

Além da ligação da Argentina, via La Paz, com o Peru e o Chile, Travassos temia sua projeção sobre o triângulo mencionado. Cochabamba já estaria ligada a Buenos Aires. A projeção Argentina se tornaria, enfim, "perigosa", caso fossem construídas vias de comunicação ligando 
Santa Cruz de La Sierra e Yacuíba (Bolívia) a Oran (Argentina). Como diz Travassos:

A direção de Oran é ainda longínqua como força dissociadora. A ponta dos trilhos apenas transpõe o Bermejo e, quando tiver atingido Yacuíba, ainda terá que percorrer cerca de $600 \mathrm{~km}$ para tingir Santa Cruz; todavia, não nos esqueçamos de que essa direção, correndo nítida para o sul, conduz diretamente a Buenos Aires, ao escoadouro natural da bacia platina. Essa circunstância pode, de um momento para outro, tornar essa direção dissociadora das mais perigosas (Travassos 1947, 100).

A linha pontilhada de Santa Cruz de La Sierra até um pouco depois de Yacuíba é exatamente a via férrea que poderia ser construída e que provocou preocupação em Travassos (Figura 4):

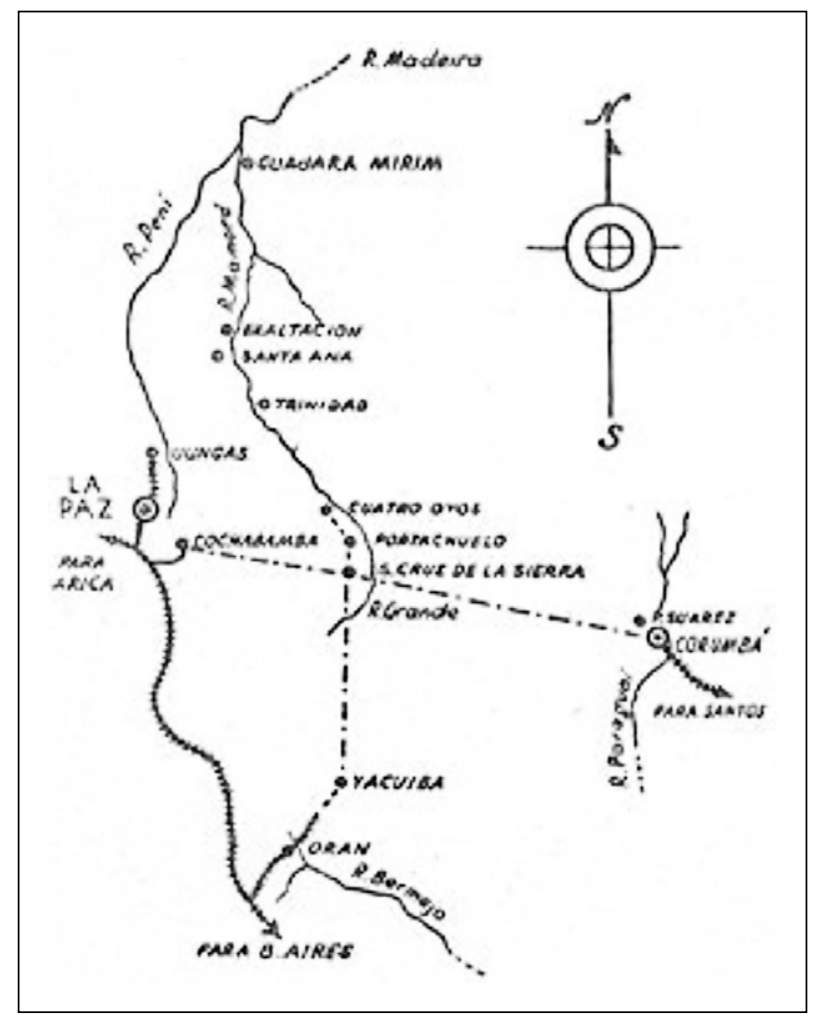

Figura 4 - Esquema das influências geopolíticas sobre Santa Cruz de la Sierra.

Fonte: Travassos $(1947,101)$. 
Partindo do que entende como uma ameaça ao Brasil, Travassos (1947) sugeriu duas respostas geopolíticas por meio da construção de infraestrutura de transporte. Uma, na Bacia do Prata, e outra, na Bacia Amazônica. Chamadas de "Ações Neutralizantes sobre a Bacia do Prata", teriam a função de fortalecer a estrada de ferro São Paulo-Rio Grande:

[...] aumentando-lhe o rendimento, e ligar o oceano ao Paraná, prolongando as linhas de Ponta Grossa ao Pôrto de Guaíra e do Pôrto União à Foz do Iguaçu; enfim consolidar a Noroeste, em toda a extensão do termo, pondo-a à altura de suportar em boas condições o escoamento dos produtos mediterrâneos, do Paraguai e da Bolívia (Travassos 1947, 40).

Já a resposta na Bacia Amazônica dependeria principalmente da exploração do potencial hidroviário do rio Madeira (Brasil), ligado aos rios Mamoré e Beni (Bolívia) e ao rio Madre de Diós do Peru e da ferrovia Madeira-Mamoré, que ligava a cidade de Porto Velho a Guajará Mirim cidade através da qual o Brasil poderia chegar, primeiro por via férrea e, em seguida, por hidrovia (Rio Mamoré e Rio Grande, vide Figura 3) a Santa Cruz de La Sierra e Sucre. Além de sua preocupação em relação à projeção argentina sobre a Bacia do Prata, Travassos identifica a aproximação dos EUA sobre a Bacia Amazônica.

Os EUA já tinham forte presença no mar do Caribe (chamado pelo autor de mar das Antilhas) e no Canal do Panamá. Assim, entendia Travassos que já estava esse país em situação geopolítica favorável para "canalizar-se por onde fôr mais fácil e necessário escoarem-se os seus interesses econômicos" (Travassos 1947, 112), que naquela época eram a busca de borracha e petróleo, pelas bacias do Orinoco e do Madalena, que seriam:

[...] linhas de penetração por excelência para quaisquer influências econômicas, provindas do mediterrâneo americano. Não só abrem as portas aos longos vales longitudinais dos Andes como, por contato direto, comunicam com o vale do Amazonas, e, indiretamente, pelos nudos e pasos (abertas andinas) comunicam ainda com êsse vale e com a bacia do Prata (Travassos 1947, 114). ${ }^{11}$

Para mitigar essa influência ao também fazer-se presente na região, Travassos sugere o melhoramento das ligações hidroviárias do Rio Negro (Brasil) ao rio Orinoco (Venezuela), rio Madalena e rio Putumayo (Colômbia) e o melhoramento das ligações do rio Branco (Brasil) ao rio Caura (Venezuela) e o rio Trombetas (Guiana). Outra solução seria promover ligações com os nudos e pasos. Deste modo, escreve Travassos:

[...] quando as possibilidades carreadoras da Amazônia se verificarem a pleno rendimento e conjugadamente com as abertas andinas, 
excluindo apenas o Paso de Uspalata, as bocas do Amazonas despejarão no Atlântico grande parte da riqueza do centro e da vertente ocidental do continente $(1947,77)$.

O trabalho de Travassos refere a projeção logística do Brasil na região andina e amazônica como meios fundamentais à integração nacional. $\mathrm{O}$ mapa a partir do qual desenvolveu sua análise em âmbito doméstico é o sugerido por Delgado de Carvalho, como diz Travassos "nada conhecemos de melhor que o admitido pelo professor Delgado de Carvalho, isto é, o Brasil permitindo quatro regiões naturais, a saber: o Brasil Amazônico, o Nordeste Subequatorial, a Vertente Oriental dos Planaltos e o Brasil Platino" (Travassos 1947, 125). Abaixo segue uma figura como representação do mapa sugerido.

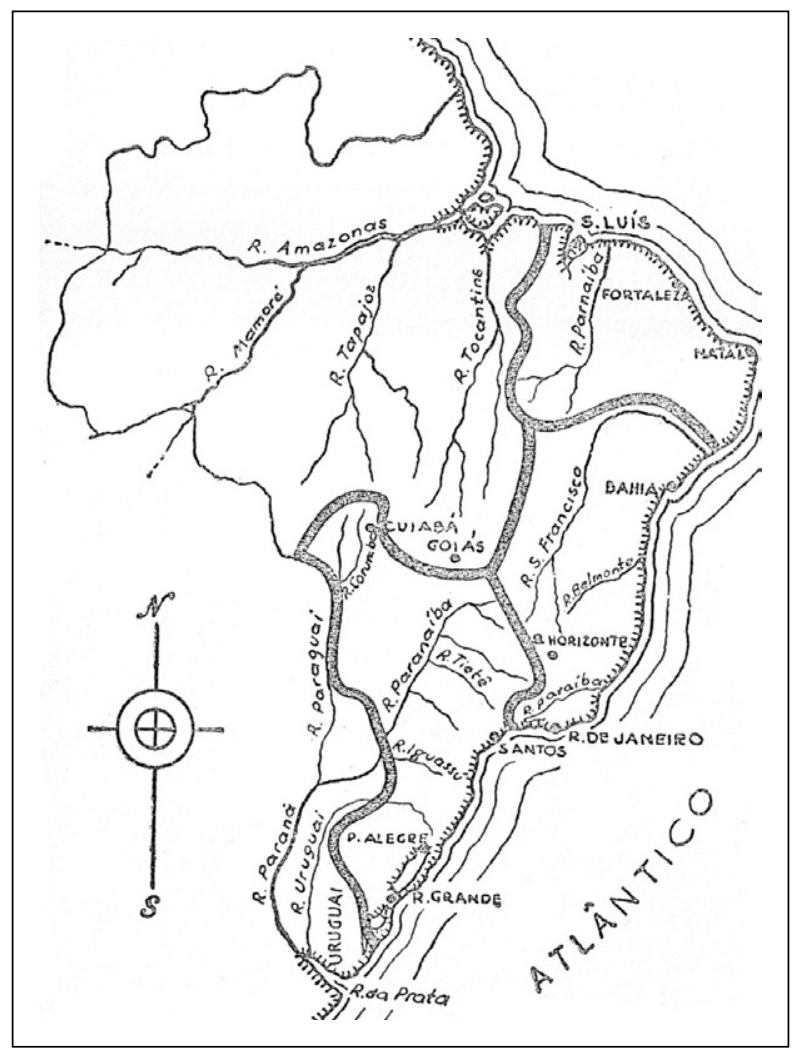

Figura 5 - Regiões Naturais do Brasil.

Fonte: Travassos $(1947,127)$. 
O Brasil Amazônico corresponde à maior porção de terra ao lado esquerdo da figura. $\mathrm{O}$ Brasil Platino, à porção de terra ao lado esquerdo e ao sul do Brasil Amazônico, já o Nordeste Subequatorial corresponde ao "quadrante" da parte superior direita, enquanto a Vertente Oriental dos Planaltos corresponde ao quadrante do lado direito. Sobre o Brasil Amazônico e o Brasil Platino, Travassos diz:

O Brasil Amazônico se comunica de modo mais direto com o oceano, por isso que dispõe do Rio Amazonas como via natural. E sua capacidade de penetração é mais ampla, pois o vale amazônico é o grande coletor do formidável anfiteatro que se arqueia de Caracas a La Paz. O Brasil Platino, apesar de que exija meios artificiais para ligar-se ao oceano, dispõe de portos com suficiente capacidade de atração na costa e dos estímulos de dois países mediterrâneos [Bolívia e Paraguai] que naturalmente reagem contra a fôrça centrípeta do Prata: - o sul de Mato Grosso, prolongando os territórios paulista e paranaense, representa a sua fôrça de penetração (Travassos 1947, 129).

O perfil geográfico de ambas as regiões determina as ações mais adequadas a serem tomadas para o desenvolvimento de uma logística estratégica. ${ }^{12}$ Conforme explanado, o principal meio de transporte a ser explorado na Bacia Amazônica seria a hidrovia, enquanto na Bacia Platina seriam as ferrovias (Travassos 1947). As duas bacias, no espectro doméstico, estariam ligadas pelo que Travassos chama de "Brasil Longitudinal", que corresponde à:

[...] Vertente Oriental dos Planaltos e [a]o Norte Subequatorial - que se prolongam de modo a justificar o título que lhe atribuímos de Brasil Longitudinal, chamado a como que estabelecer a ligação entre as duas vastíssimas regiões denominadas Brasil Amazônico e o Brasil Platino. À extensa linha de costa convexa que se estende da Guanabara ao Golfão do São Luís corresponde, como uma sorte de corda, a linha terrestre balizada pelo vale superior e médio do São Francisco e do Parnaíba.

Quer dizer que excentricamente, por via marítima, ou concentricamente, por vias terrestres, o papel funcional dessas regiões é de ligar, homogeneizar, amarrar os dois brasis essenciais, do ponto de vista continental, o platino e o amazônico (Travassos 1947, 131).

A importância estratégica do "Brasil das Bacias" só se mantém à medida que o país consiga integrá-lo por meio do Brasil Longitudinal. A partir dessa observação, Travassos analisou, em miúdos, duas características das vias de comunicação no Brasil. A primeira é exatamente sua 
penetração (linhas de penetração) nos demais países da América do Sul, por meio da Noroeste, Madeira Mamoré e hidrovias (Bacia Amazônica), como diz o autor:

[...] os desenvolvimentos da Noroeste e o milagre da MadeiraMamoré; o tráfego da rêde paulista e o movimento portuário de Santos, tão bem como as correntes dos transportes fluviais do Amazonas, isso quanto às linhas de penetração (Travassos 1947, 132).

A segunda seria sua ligação com o Brasil Longitudinal. Continua o autor:

[...] quanto à ligação delas, aí temos a São Luís-Terezina e a estrada Petrolina-Paulista, bem como os prolongamentos ferroviários que já atingem a fronteira de Minas à procura da rêde baiana, sem contar as linhas de cabotagem e o tráfego aéreo (Travassos 1947, 132).

Essas "linhas de penetração" somadas a suas ligações, contudo, não evidenciavam muita circulação dentro do "Brasil das Bacias". Isso fica evidente quando o autor explica a importância e a fragilidade do estado do Mato Grosso, que ainda não tinha sido dividido. O Mato Grosso seria importante devido a sua localização central no continente americano, mas permanecia objeto de preocupação de Travassos (1947), devido a seu "baixo teor demográfico" (Travassos 1947, 240) e seu "afastamento aos centros propulsores do país” (idem). A Projeção Continental do Brasil somente poderia ser exercida em sua plenitude se o Mato Grosso, e demais regiões ermas da Bacia Amazônica, fossem devidamente povoadas. Essa percepção pode ser identificada na seguinte passagem:

Para Oeste! Tem toda a concisão das verdadeiras fórmulas políticas. Quer dizer antes de tudo compreensão e definição da facies geográfica do Continente e do Brasil. Em seguida, comunicações, colonização, atividade industrial. Por sua vez, nesses desdobramentos se encontram outros aspectos ligados à escolha dos meios de transporte, às questões de saneamento e educação, à noção de ordem de urgência dos cometimentos (Travassos 1947, 245).

A obra de Travassos merece especial destaque. O autor pontuou claramente a relação entre a importância da integração nacional para a projeção dos interesses do Brasil na América do Sul. Como sugerido pela Figura 1, a dos Antagonismos Continentais, a questão da "Defesa" não aparece em seu sentido mais bruto, isto é, de planos de defesa ou ataque, mas permeia toda a sua argumentação. $\mathrm{O}$ autor aponta que o Brasil deve fazer frente à projeção de dois concorrentes na região, e a melhor maneira de fazê-lo é com a projeção de nossa logística estratégica, isto é, a expansão e constante melhora das infraestruturas de transporte e das atividades econômicas. 
Quando menciona a importância do Mato Grosso, ressalva os provimentos dessas infraestruturas e importância da promoção das atividades econômicas. Para Travassos (1947), a solução econômica e logística (estratégica) seria fundamental para qualquer respaldo militar.

Essa relação entre integração nacional e geopolítica também ganha a atenção de Golbery do Couto e Silva. Na primeira edição de "Aspectos Geopolíticos do Brasil” de 1952, Golbery dividiu o estudo da geopolítica em duas, a interna e a externa. A primeira estaria preocupada com a ideia de "melhorar o espaço nacional", enquanto a segunda olhou para o "problema fundamental da segurança e da defesa” (Silva 1967, 62). Golbery estava ciente de que o país continuava sendo um território desigual e mal integrado. Para remediar essa situação, o Brasil deveria: "controlar a direção dos fluxos migratórios, constituir polos de desenvolvimento nas áreas continentais fronteiriças, desenvolver uma rede de ferrovias e de comunicações aéreas e fazer uso das vias navegáveis" (Silva 1967, 30).

Silva (1967) parte de uma análise do mapa nacional segmentado em cinco partes. A primeira parte seria o que o autor chama de "Núcleo Central", localizado na parte inferior ao lado direito da Figura 6, formado pelos estados do Rio de Janeiro, Minas Gerais e São Paulo. As outras três regiões são chamadas por Golbery de "penínsulas", que são ligadas por "istmos" (rodovias e ferrovias). A última região seria uma verdadeira "ilha” de difícil acesso, que seria a região amazônica (Silva 1967). Vide figura 6.

A primeira península, na parte superior direita da figura, seria formada por parte do Recôncavo Baiano, Recife e Fortaleza, "também unificada por apreciável trama de ferrovias e rodovias" (Silva 1967, 46), a segunda (na parte inferior da figura) estaria na região Sul, seria a península que "se estende pelo Paraná e Santa Catarina, alargando-se depois para englobar todo o território do Rio Grande do Sul” (1967, 47). A terceira península, na parte inferior e ao lado esquerdo do da figura, seria a região CentroOeste, onde ficam as cidades de Cuiabá, Campo Grande e Goiânia. Por fim, a última região da representação cartográfica geopolítica de Golbery, correspondente à maior porção listrada ao lado superior esquerdo da imagem, é a Ilha Amazônica ou Hileia "isolada, tributária do caudal amazônico e nitidamente dependente das ligações marítimas” (1967, 47). Grosso modo, a região Centro-Oeste, assim como a Hileia Amazônica seriam o:

[...] Brasil marginal, inexplorado em sua maior parte, desvitalizado pela falta de gente e de energia criadora, e o qual nos cumpre incorporar realmente à nação, integrando-o na comunidade nacional e valorizando a sua grande expressão física hoje ainda quase completamente passiva (Silva 1967, 44). 


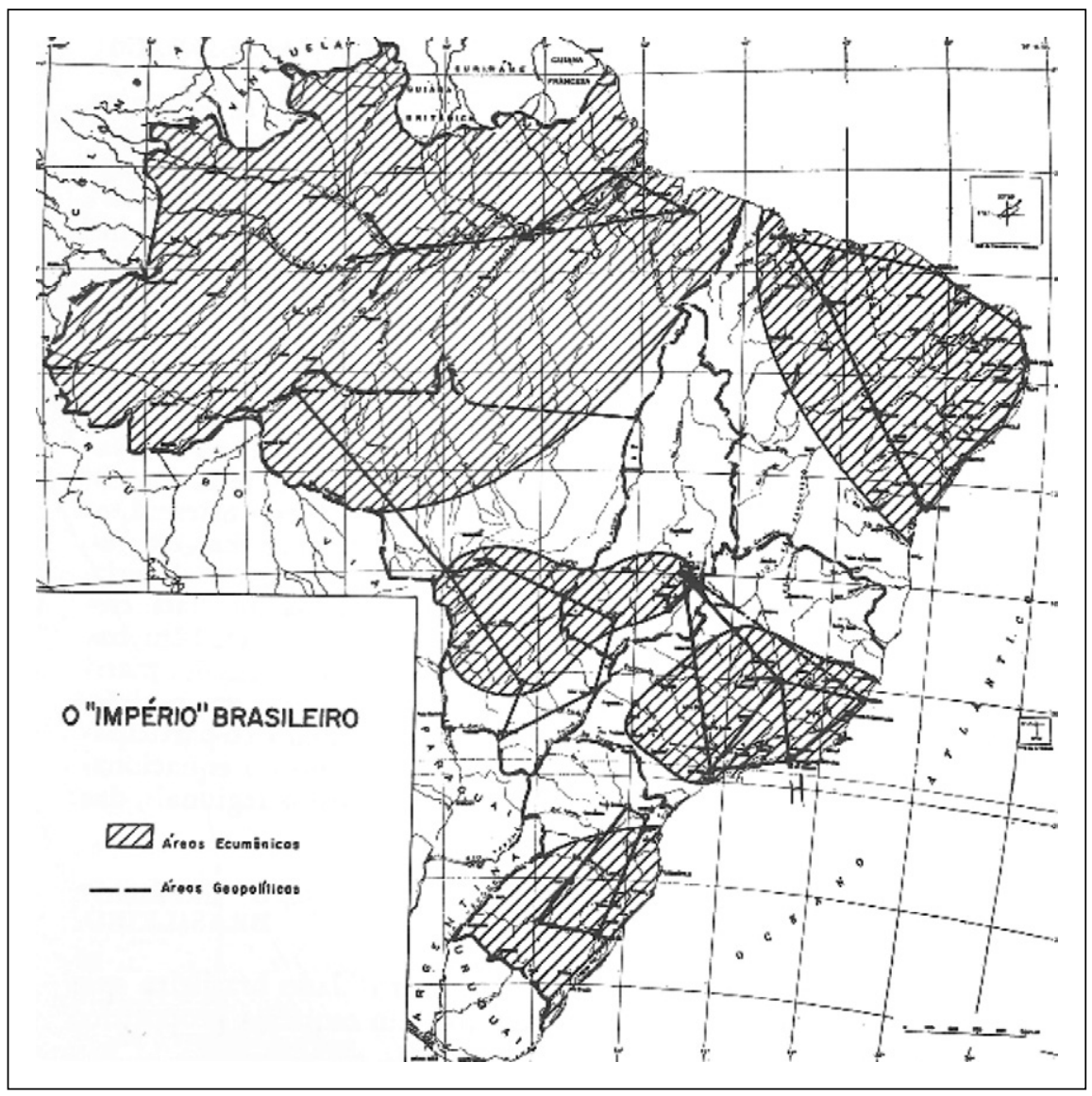

Figura 6-O "Império" Brasileiro.

Fonte: Silva (1981, 90).

Segundo Golbery, esse vazio poderia atrair a cobiça internacional, como verificamos no seguinte trecho: "Mas é preciso que não esqueçamos que o vácuo de poder, como centro de baixas pressões, atrai de todos os quadrantes os ventos desenfreados da cobiça” (Silva 1967, 44). A solução para essa situação demográfica e econômica seria precisamente a melhoria da infraestrutura de transportes no país, ou seja:

A primeira tarefa, pois, visando à integração e valorização do território nacional, há de ser forçosamente a de vitalizar esses istmos de circulação, de maneira a, de um lado, articular solidamente de norte a sul nossa atual base ecumênica e, de outro lado, consolidar o avanço 
já esboçado para noroeste, a partir do núcleo central que, geográfica e historicamente, é a verdadeira plataforma para penetração e conquista do interior (Silva 1967, 47).

\section{CONSIDERAÇÕES FINAIS}

O argumento que este estudo propôs ser transversal à literatura geopolítica brasileira, entre as décadas de 1910 e 1950, foi identificado. Todos os geopolíticos brasileiros, considerados pelos revisores como importantes geopolíticos entre 1910 e 1950, compartilhavam o entendimento de que para melhor defender-se o Brasil precisaria melhor integrar-se. Estudiosos contemporâneos da geopolítica brasileira também concordam que o campo de estudos se caracteriza por sua atenção à relação entre o desenvolvimento dos meios de transporte e da integração para uma Defesa Nacional mais eficiente, segundo Miyamoto:

[…] de acordo com os pressupostos não só econômicos, como também geopolíticos, sem integrar o território é inviável o seu próprio fortalecimento. Uma das condições primeiras deve referir-se, então, à intensificação dos meios de transporte para ocupar o espaço. Visivelmente foi essa a preocupação daqueles que se dedicaram ao estudo da geografia dos transportes no país. Essa é uma das discussões que sempre estiveram à baila, não só pelos geopolíticos, como também por planejadores ligados diretamente a entidades governamentais (Miyamoto 1995, 149-50).

Freitas (2004), que analisou principalmente o pensamento de Golbery, ${ }^{13}$ chega a conclusão semelhante quando diz que as ideias geopolíticas defendidas antes da Segunda Guerra Mundial "têm como principais enfoques o antagonismo Brasil-Argentina, a questão dos transportes (vertebração interna) e da divisão territorial” (Freitas 2004, 119). A conclusão similar chega Costa (1992), quando diz:

A imensidão do território, o povoamento disperso e o fraco poder de articulação inter-regional da economia agrário-exportadora, ao lado de um poder central baseado na composição política com as oligarquias locais e regionais, representaram, desde a formação do Estado nacional, em 1822, um quadro distante de um federalismo clássico (como o norte-americano) e mais próximo de um conjunto político-administrativo-territorial unitário extremamente desarticulado em nível nacional. Esse era o pano de fundo para as ideias de integração nacional que, sob vários matizes, marcaram o discurso político-territorial de muitos setores do poder estatal ou próximos deste. 
Daí por que a base técnico-científica fornecida pela geografia tornou-se elemento importante para a formulação dessas políticas (Costa 1992, 192).

Para além de Costa (1992), como indicado na passagem acima, Miyamoto (1995) deixou claro que a preocupação da integração nacional, além de ser tema explorado pelos geopolíticos, também foi foco da atenção de "planejadores ligados diretamente a entidades governamentais". Freitas, de forma mais clara, sugere essa relação entre a geopolítica brasileira e as políticas públicas quando conclui em seu estudo que as "teses geopolíticas elaboradas no Brasil a partir da década de 1920 não deixam, naturalmente, de obedecer a esse princípio básico, estando subjacente a todas elas uma nítida propensão para sua aplicação prática (geopolítica aplicada)" (Freitas 2004, 113).

Assim, além de ter sido verificado que havia um consenso entre os estudos de geopolítica de maior destaque no período proposto, ou seja, a ideia central de que para melhor defender-se o brasil precisaria melhor integrar-se, também se verificou que havia uma proximidade entre o pensamento geopolítico e projetos nacionais de desenvolvimento de infraestrutura. A partir deste achado, sugere-se, para investigação futura, mais ampla pesquisa para que sejam verificados os impactos do pensamento geopolítico brasileiro e a potencial relação entre este e o desenho e implementação da infraestrutura nacional, notadamente aquela de meios de transporte.

\section{REFERÊNCIAS}

Anselmo, Rita de Cássia Souza. 2000. "Geografia e Geopolítica na Formação Nacional Brasileira - Everardo Adolpho Backheuser”. Tese de Doutorado em Geografia, Universidade Estadual Paulista Júlio de Mesquita Filho.

Backheuser, Everardo. 1933. Problemas do Brasil (Estrutura Geopolítica). Rio de Janeiro: Grupo Editor OMNIA.

1948. Curso de Geopolitica Gerale do Brasil. Rio de Janeiro: Gráfica Laemmert.

Carvalho, Delgado. 1913. Geografia do Brasil. Rio de Janeiro: Impressões Artísticas.

Carvalho, Elyseo. 1921. O fator geográfico na política brasileira. Rio de Janeiro: S.A. Monitor Mercantil.

Cidade, Francisco de Paula. 1940. Notas de Geografia Militar Sul-Americana. 2. ed. Rio de Janeiro: Biblioteca Militar. 
Costa, Wanderley Messias da. 1992. Geografia política e geopolítica: discursos sobre o território e o poder. São Paulo: Editora da Universidade de São Paulo.

Farias, Hélio C. 2017. "A estratégia do Brasil na África: fundamentos geopolíticos e mecanismos de financiamento no ciclo recente de expansão econômica (20032014)". Tese de doutorado em Economia Política Internacional, Universidade Federal do Rio de Janeiro (UFRJ), Rio de Janeiro.

Freitas, Jorge Manuel da Costa. 2004. A escola geopolítica brasileira. Rio de Janeiro: Biblioteca do Exército Ed.

Kress, M. 2002. Operational Logistics: The Art and Science of Sustaining Military Operations. New York: Springer Science; Business Media New York.

Martin, André Roberto. 2018. Brasil, Geopolitica e Poder Mundial: o anti-Golbery. São Paulo: Hucitec.

Miyamoto, Shiguenoli. 1995. Geopolítica e Poder no Brasil. Campinas, SP: Papirus Editora.

Rodrigues, Lysias A. 1947. Geopolítica do Brasil. Biblioteca Militar Volume CXI. Rio de Janeiro.

Rooy, Gregor G. A. A. De. 2019. "Um estudo da influência do pensamento geopolítico na concepção do Programa de Integração Nacional (PIN)”. Dissertação de Mestrado em Ciências Militares, Instituto Meira Mattos da Escola de Comando e Estado-Maior do Exército (ECEME), Rio de Janeiro.

Silva, Golbery do Couto. 1967. Geopolítica do Brasil. Rio de Janeiro: Livraria José Olympio Editora.

Silva, Golbery do Couto. 1981. Conjuntura Política Nacional o Poder Executivo e Geopolítica do Brasil. Rio de Janeiro: Livraria José Olympio Editora.

Travassos, Mario. 1947. Projeção Continental do Brasil. Brasiliana Biblioteca Pedagógica Brasileira. 


\section{NOTAS}

1. Alexandre de Gusmão, Visconde de Rio Branco e o Barão de Rio Branco foram três diplomatas de destaque no Brasil, o primeiro durante o século XVIII, o segundo durante o século XIX, e o terceiro no fim do século XIX e início do século XX.

2. Embora Elysio Carvalho apresente um típico raciocínio geopolítico, correlacionando território, poder, política nacional e inserção internacional, sua obra é pouco lembrada. Martin (2018) atribui ao relativo esquecimento da obra de Elysio Carvalho duas ordens de fatores. De um lado, as suas posições políticas socialistas e anarquistas. De outro, a própria produção multifacetada do autor, que incluía literatura, direito, filosofia. Sendo difícil, portanto, caracterizá-lo como um autor clássico de geopolítica.

3. O termo "vias de comunicação", comumente usado pelos autores brasileiros de geopolítica como Carvalho, Cidade, Rodrigues e Couto e Silva, refere-se aos meios de transporte, caminhos ou infraestruturas de transporte que pudessem prover o deslocamento de pessoas, materiais e/ou mercadorias. Nas obras estudadas não encontramos definição clara do termo, porém seu significado é percebido à medida que os autores relacionam o termo às infraestruturas de transporte ou caminhos em geral.

4. A obra de Golbery que usamos neste estudo é aquela editada em 1967, Geopolítica do Brasil. Este livro é, na realidade, a reunião de diversos textos do autor publicados em diferentes anos da década de 1950 e 1960. São eles "Aspectos Geopolíticos do Brasil” com versões publicadas em 1952, 1959 e 1960; "Geopolítica e Estratégia", publicado em 1959, "Dois Polos de Segurança Nacional na América Latina” publicado em 1959, "Áreas Internacionais de Entendimentos e Áreas de Atrito" publicado em 1959 e "O Brasil e a Defesa do Ocidente" publicado em 1958.

5. A edição que usamos da obra de Travassos é sua quarta edição, impressa em 1947; destacamos que essa obra, em sua primeira edição impressa em 1930, chamava-se Aspectos Geográficos Sul-Americanos.

6. Os Tratados mencionados por Carvalho são: Tratado de Tordesilhas (1494), Tratado de Madrid (1750) e Tratado de Santo Ildefonso (1777) entre Portugal e Espanha, o Tratado de Utrecht (1713) entre Portugal e França, o Tratado de Petrópolis (1903) entre Brasil e Bolívia, o Tratado de 1906 entre Brasil e Países Baixos, o arbitramento entre Brasil e Argentina com o laudo do presidente Cleveland (EUA) em 1895, o tratado de 1907 com a Colômbia, o tratado condicional com o Equador em 1904, e o tratado de 1910 com o Uruguai (Carvalho 1913). 
7. Anos depois da publicação de seu livro em 1947, o Estado brasileiro, em acordo com o Estado paraguaio, inicia em 1971 a construção da Usina Hidrelétrica de Itaipu no Punctum de Iguaçu.

8. O trabalho de Rita de Cássia Souza Anselmo (2000) traz um importante resgate para contribuições de Backheuser no debate sobre a redivisão territorial do Brasil em unidades federativas. Em seu estudo, a autora identifica 64 unidades fundamentais no território brasileiro, e propôs reagrupá-las em 16 estados e 6 territórios federais. Seria uma divisão ideal, baseada no critério de unidades equipotentes, que, segundo Rodrigues, contribuiria para manter a unidade nacional e romper com os regionalismos.

9. No ano da publicação de seu livro, a República do Suriname pertencia aos Países Baixos e se chamava Guiana Holandesa. A República do Suriname só se tornou independente em 1975. Já a República Cooperativa da Guiana, independente desde 1966, pertencia ao Reino Unido e se chamava British Guiana.

10. Mário Travassos publicou a sua principal obra Projeção Continental do Brasil em 1931. Utiliza-se, neste artigo, a $4^{\mathrm{a}}$ edição do livro, publicada em 1947.

11. Os nudos são formas topológicas "que balizam os centros de dispersão orográfica das várias seções da grande cordilheira”, já os pasos “indicam as passagens, por assim dizer naturais (colos), de uma para outra vertente" (Travassos 1947, 73).

12. A logística estratégica é aquela pensada "rotineiramente durante tempos de paz através de um trabalho bem esquematizado" (Kress 2002, 26, tradução nossa); os planos da logística estratégica são "robustos e têm um efeito de longa duração nas capacidades da operação militar" (Kress 2002, 26, tradução nossa). Kress identifica quatro dimensões dessa logística, que são a tecnológica, a industrial, a de transportes e a de inventário/estoques. Portanto, uma logística estratégica pensa em estruturas que poderão causar impacto direto ou indireto, porém de longa duração à atividade/operações militares.

13. A obra de Freitas analisa, principalmente, os estudos de Golbery, Therezinha de Castro e Meira Mattos. Os dois últimos autores também fundamentais da geopolítica brasileira, mas que não tiveram contribuição expressiva durante o período aqui analisado. 


\section{A INTEGRAÇÃO NACIONAL ANALISADA \\ SEGUNDO A GEOPOLÍTICA BRASILEIRA ENTRE 1910-1950}

\section{RESUMO}

O estudo faz leitura de revisores da geopolítica brasileira para identificar seus principais geopolíticos entre 1910-1950, período de continuidade no pensamento geopolítico relativo à importância da integração nacional. Consecutivamente, faz-se releitura das principais obras da época concluindo-se que o principal argumento geopolítico foi para melhor defender-se é preciso melhor integrar-se.

Palavras-Chave: Geopolítica, Análise, Meios de Transporte, Integração.

\section{ABSTRACT}

This study analyses the works of reviewers of Brazilian Geopolitics to identify core geopoliticians between 1910-1950, a period of continuation of geopolitical thought regarding the relevance of national integration. Consecutively, the most relevant works of the period are studied and the main geopolitical argument identified is to better protect itself it needs to better integrate.

Keywords: Geopolitics, Analysis, Means of Transportation, Integration. 